\title{
The Effect of Applying Analytical Procedures on Understanding Business Environment in Light of Using Accounting Information Systems in Auditing
}

\author{
Thaer Faisal Abdelrahim Qushtom ${ }^{1}$ \\ ${ }^{1}$ Accounting Sciences Department, Faculty of Economics and Administrative Sciences, Zarqa University, Zarqa, \\ Jordan
}

Correspondence: Thaer Faisal Abdelrahim Qushtom, Accounting Sciences Department, Faculty of Economics and Administrative Sciences, Zarqa University, Az-Zarqa, P.O. Box 132222, Zarqa 13132, Jordan. Tel: 962-5-382-1100. E-mail: th_ko1985@yahoo.com

Received: September 18, 2020

Accepted: November 17, $2020 \quad$ Online Published: December 20, 2020

doi:10.5430/rwe.v11n6p291

URL: https://doi.org/10.5430/rwe.v11n6p291

\begin{abstract}
Since the entire world is moving with a steady acceleration to invest the technology in various fields and professions, exploring the effectiveness of these technologies in achieving the desired goals became an imperative need. Accordingly, the strengths and weaknesses that surround these systems could be identified. In this vein, the current study aimed to explore the effect of using client's accounting information systems by auditors on the effectiveness of analytical procedures in understanding business environment of entities, assessing the going concern of entities, and estimating potential misstatements in financial reports. To carry out the current study quantitative approach was adopted. Thus, a survey questionnaire was designed and distributed to 164 qualified and unqualified person who work in auditing profession in Jordan. In order to test hypotheses, a multivariate regression analysis tests were performed. The results showed that using client's accounting information systems by auditors has a significant positive effect on the relationship between analytical procedures and understanding business environment of entities, and estimating potential misstatements in financial reports. Conversely, the results showed that using client's accounting information systems by auditors has a significant negative effect on the relationship between analytical procedures and assessing the going concern of entities. The results imply that, auditors should benefit from using clients' accounting information systems in enhancing their understanding of business environment and estimating potential misstatements in financial reports. On the other hand, they should not depend extensively on these systems in assessing the going concern of these entities.
\end{abstract}

Keywords: accounting information systems, analytical procedures, understanding business environment, going concern, misstatements in financial reports

\section{Introduction}

The outputs of accounting information systems could be consider one of the most important sources that investment and administrative decision-makers rely in general (Appelbaum et al., 2017; McCallig et al., 2019). Therefore, the outputs of these systems, such as financial statements, are subject to precise examination by external auditors (Vanstraelen \& Schelleman, 2017; Afshar et al., 2019). Nowadays, in light of the widespread technological development, external auditors use computers to conduct audits, analyze and comparison procedures (Byrnes et al., 2018). Accordingly, new and advanced methods have been emerged and used by auditors to carry out these operations, especially for conducting analytical procedures (Rozario \& Vasarhelyi, 2018; Nazarova et al., 2019). Analytical procedures are considered some of the basic procedures that accompany auditing process from its inception to the end (Appelbaum et al., 2018; Rose et al., 2020). In this context, Moolman (2017) explained that external auditors rely extensively on analytical procedures in determining their preliminary estimates during planning phase, understanding company's environment, determining the required tests, and issuing the final report (Smith and Stephens, 2020). According to Rose et al., (2020), analytical procedures are to make comparisons between financial and non-financial data for one company for more than one fiscal year, and the data for similar companies. Based on the aforementioned, the importance of analytical procedures in auditing process and the use of technology in conducting these procedures, such as using accounting information systems, are obvious. 
As mentioned above, analytical procedures are some of the most important procedures in auditing process that auditors perform to issue a neutral professional opinion on the fairness of financial statements (Anderson et al., 2019). Therefore, conducting analytical procedures in an efficient and effective manner in light of using accounting information systems, which includes many areas of creativity and innovation, requires broad knowledge and high skills to reach high levels of confidence in the quality of auditing process and its outputs (Austin et al., 2020). Thus, the problem of the current study is that the use of accounting information systems in analytical procedures depends not only on one standard mechanism, but also includes many different and divers approaches and methods (Rozario \& Vasarhelyi, 2018). Accordingly, some shortcomings and weaknesses in the efficiency and effectiveness of implementing analytical procedures may result, especially in understanding the business environment of entity.

\subsection{Questions of Study}

According to the aforementioned, the main question of the current study that need to be answered, to ensure the efficiency and effectiveness of analytical procedures in auditing process in light of using accounting information systems in entities, is:

Main.Q: What is the effect of using accounting information systems by auditors on the effectiveness and efficiency of analytical procedures in understanding the business environment of entity?

In order to answer the prior main question, two sub-questions have to be answered, which are:

Sub.Q1: What is the effect of using accounting information systems by auditors on the effectiveness and efficiency of analytical procedures in assessing the company's going concern?

Sub.Q2: What is the effect of using accounting information systems by auditors on the effectiveness and efficiency of analytical procedures in estimating potential misstatements in financial statements?

\subsection{Aims of Study}

As defined previously, the main aim of the current study is to explore the effect of using accounting information systems on the effectiveness and efficiency of analytical procedures in understanding the business environment of entity. In addition, the present study seeks to clarify the feasibility of using accounting information systems and propose recommendations to auditors regarding the possible enhancements to increase the effectiveness of using these systems in analytical procedures in auditing process.

\subsection{Importance of Study}

The importance of the current study is in its endeavor to shed the light on the effectiveness of implementing one of the main procedures in auditing process, namely analytical procedures, in understanding the entity's' business environment through using modern technological means represented by accounting information systems. As the entire world is moving with a steady acceleration to invest modern technologies in various fields and professions, it has become imperative to explore the efficiency and effectiveness of these technological means in achieving the desired goals. Based on that, the strengths and weaknesses that surround these systems would be identified, which help in enhancing the useful ones and addressing the harmful ones. Due to the importance of analytical procedures in auditing process as a whole, and its fundamental impact on the outcome of auditing process, maintaining the efficiency and effectiveness of these procedures when using accounting information systems by external auditors should be ensured.

\section{Literature Review}

Over years, many studies have focused on exploring the effect of information systems on different aspects of business and professions, including auditing profession. Accordingly, many findings have been presented in the literature. In the field of the current study, Rose et al., (2020) have carried out field study to explore if extensive analytical explanation improves the quality of audit. Rose et al., have found that generating extensive explanation by analytical procedures create an overload information that may reduce the quality of audit. Similarly, Anderson et al., (2019) have explored the effects of rich data visualization and analytical procedure on auditors' judgment. Accordingly, they have found that the rich data visualization inflates the audit procedure categorization effects in auditors' judgments. In addition, it increases the auditors' assessment of outliers risks when the prior procedures were categorized as risk assessment. On the other hand, Leonov et al., (2020) have carried out a study to explore if it is applicable to use analytical tools in performing analytical procedures to assess the organization's involvement in suspicious operations. Leonov et al., found that using analytical tools in checking financial statements allow auditors to enhance the effectiveness of analytical procedures in detecting suspicious operations and transactions. In the same context, Matrood et al., (2019) have explored the effect of analytical procedures in improving the performance of 
auditing process. The researchers have found that analytical procedures help in improving the planning and timing of auditing process. In addition, the lack of required training of Iraqi auditors creates an obstacle regarding their implementation of analytical procedures. In 2019, Dolinska has conducted a study to propose a model for performing analytical procedures using internal systems to help Ukraine banks to avoid the liquidation risks. Dolinska's proposed model explained that the timely implementation of analytical procedures in a manner that includes the planning stages, task performance and outcome might help banks in reducing the liquidation risks. With regard to accounting information systems, AL-Amro et al., (2017) have performed a study to identify the effect of electronic accounting information systems risks on financial reporting quality in Jordanian commercial banks. The researchers have found that the risks that surround electronic accounting information systems, specifically data entry risk, data managing risk, data outputs risk, and environmental risks, affect significantly the quality of financial reports in Jordanian commercial banks. Further, Castka et al., (2020) have carried out a study to investigate the role of technology in improving the timeliness and veracity of social and environmental audits. Castka et al., have discoverd that using technology in audit enhances the audit governance, the volume and variety of audited data, the velocity, veracity, and timeliness of auditing process. The existing literature, including the aforementioned studies, have focused on either analytical procedures in auditing or technological systems in performing audit. Differently, the current study has explored the strengths and weaknesses of using client's accounting information systems in implementing analytical procedures to understand the business environments of entities under audit, which make it the first study that focus on certain aspects for analytical procedures objectives.

\section{Theoritical Framework}

Accounting information systems are the primary source of providing managers with financial and non-financial information that helps them in decision-making (Van der Veeken \& Wouters, 2002). These systems are based on three main activities (input / processing / output) (Sačer \& Oluić, 2013; Sori, 2009). In this context, (Guragai et al., 2017) indicated that the dependence of input, processing, and outputs activities on human and physical elements makes them vulnerable to unintended errors or intentional manipulation to achieve specific goals. In the both cases, obtaining incorrect outputs leads to wrong and unwise decisions (Adomavicius et al., 2019). In this vein, (AL-Amro et al., 2017) explained that the sensitivity of dealing with accounting information systems increases with the presence of many entry points to amend and misrepresent their activities, and that depends extensively on the talent and the skill in dealing with information systems.

At present, accounting information systems are the primary provider for auditors with the required information in most stages of auditing process (Pura, 2017). Regarding this, (Castka et al., 2020) mentioned that the use of information technology has become essential throughout all auditing stages, either in the client's' firm or in the auditing firm. Therefore, performing the auditing process has become requiring new skills, which represented by using information technology to perform the auditing process as a whole (Tarek et al., 2017). Based on the foregoing, it seems clear that the traditional performance of auditing process in all its stages is no longer possible in light of the overall transition to the use of information technology nowadays.

Among the most important stages in performing the auditing process is the stage of analytical procedures, which are the cornerstone of the auditing process from its inception to the end. In this regard, (Anderson et al., 2019) indicated that analytical procedures stage is the main driver for the entire auditing process. In addition, (Matrood et al., 2019) mentioned that the quality of performing analytical procedures in auditing process reflects on the quality of performing the entire auditing, especially the issuance of auditor's report. In this vein, (Rose et al., 2020) explained that the implementation of analytical procedures in auditing process enables auditor to understand the audited company's business and its surrounding environment, evaluate the company's going concern (Shvyreva \& Kruglyak, 2016), and estimate potential misstatements in financial statements (Rose et al., 2020). In the same context, (Moolman, 2017) found that analytical procedures significantly compliment ratio and trend analysis during audits, specifically during going concern evaluations and identifying error and fraud, which reflects on the quality of auditor's report.

The contingency theory in IT literature indicates that the purpose of information technology is to facilitate the performance of operations and to enhance their efficiency and effectiveness at the lowest possible cost (Khazanchi, 2005). Accordingly, the use of client's accounting information systems in the implementation of analytical procedures by auditors will help in understanding the business environment of entities under audit, assessing their going concern, and estimating the potential misstatements in their financial statements efficiently and effectively.

\subsection{Hypotheses of Study}

Based on the above-mentioned theoretical discussion, the current study presents the following main hypothesis: 
M.H1. the use of client's accounting information systems by auditors enhances the relationship between the implementation of analytical procedures and understanding the business environment of entities' under audit.

Since understanding the business environment of entities under audit includes several aspects, the most important of which are the going concern of companies and the possibility of misstatements in their financial statements, two sub-hypotheses emerged from the previous main hypothesis, namely:

Sub.H1. the use of client's accounting information systems by auditors enhances the relationship between the implementation of analytical procedures and the assessment of company's going concern.

Sub.H2. the use of client's accounting information systems by auditors enhances the relationship between the implementation of analytical procedures and the estimation of potential misstatements in financial statements.

\subsection{Model of Study}

Based on the theoretical framework and the aforementioned hypotheses, Figure 1 shows the model of current study that shows the hypothesized interrelationships between the variables of study:

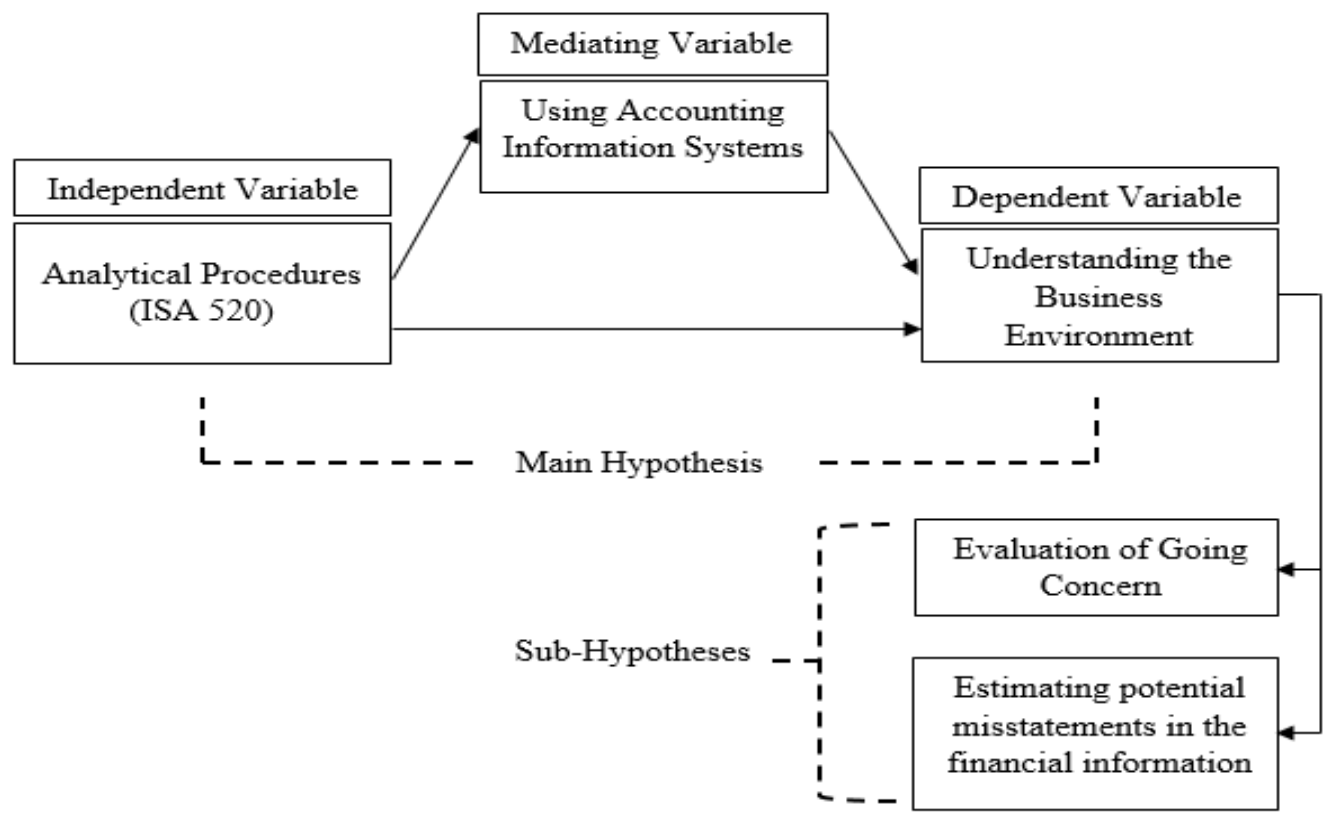

Figure 1- Model of Study

\section{Methodology of Study}

In order to carry out the current study, quantitative approach was adopted in collecting and analyzing data.

\subsection{Data Collection Method}

To collect the required data for the current study, a survey questionnaire was used. The questionnaire included 32 questions divided into four sections. The first section contained five questions related to demographic information of respondents. The second section included 10 questions that focused on the role and importance of analytical procedures in auditing process. Third section included 9 questions explored the benefits of using accounting information systems in auditing process. The fourth section included 9 questions explored the role of accounting information systems in performing analytical procedures. Excluding the demographic questions, all other questions in the questionnaire were measured by using a five-point Likert scale, which is ranged from strongly agree, agree, neutral, disagree, and strongly disagree.

\subsection{Population and Sample}

Since the current study explores one of auditing process aspects, which is analytical procedures, the population of study is all those working in the auditing profession (external auditors) in Jordan. Based on the reports of Jordan 
Association of Certified Public Accountants (JCPA), currently there are 438 certified public accountants practice the profession in Jordan (1), in addition to more than 1000 accountants (uncertified) work in auditing profession.

Accordingly, the questionnaire was distributed to 350 certified and non-certified accountants working in the audit profession (as external auditors) in Jordan. Unfortunately, the auditors' response was weak, as only 182 questionnaires were retrieved from the total distributed questionnaires. Among these retrieved questionnaires, there were 18 questionnaires not valid for analysis (answers incomplete). As a result, the study sample included 164 questionnaires, 63 of which were certified auditors, and 101 were non-certified auditors.

\subsection{Data Analysis}

Since the data of the current study is quantitative data, the analysis process relied on using the Statistical Package for the Social Sciences (SPSS software). As it is known, the SPSS helps researchers to calculate the reliability, descriptive and normality measures, as well as the multivariate regression models, which are the required measures to get the results of study and achieve its goals.

\section{- Preliminary Tests}

Before proceeding to test the main hypotheses of the current study, some preliminary test were performed, namely: reliability of questionnaires, descriptive and normality tests. These tests were required to ensure the validity of data collection instrument and the distribution of questionnaires. The questionnaires' reliability was measured by using Cronbach Alpha. The result of measuring Cronbach Alpha was shown in table 1. Based on the results in Table 1, the reliability of questionnaire is acceptable, as the lower acceptable level of Cronbach Alpha is 0.70 (Pallant, 2005).

Table 1. Cronbach Alpha Results - Reliability Test

\begin{tabular}{cc}
\hline Cronbach's Alpha & N of Items \\
\hline 0.94 & 33 \\
\hline Number of questionnaires 164 & \\
\hline
\end{tabular}

After testing the questionnaires' reliability, the descriptive statistics and normality distribution of questionnaires were measured. The descriptive statistics represented by the mean, standard deviation, minimum, and maximum, while the normality distribution of questionnaires was measured by Skewness and Kurtosis measures. The descriptive and normality results are shown in Table 2 .

Table 2. Descriptive statistics and Normality Tests of variables

\begin{tabular}{|c|c|c|c|c|c|c|}
\hline Variable & Mean & Std. Dev. & Min & $\operatorname{Max}$ & Skewness & Kurtosis \\
\hline Ana_Pro & 4.05 & 0.53 & 2.10 & 5 & -1.01 & 2.21 \\
\hline AIS_Usage & 4.05 & 0.52 & 2.11 & 5 & -1.06 & 2.41 \\
\hline Under_Buss & 4.05 & 0.52 & 2.11 & 5 & -0.94 & 2.03 \\
\hline Eva_Go_Co & 4.04 & 0.68 & 2 & 5 & -0.51 & 0.64 \\
\hline Est_Misstat & 4.04 & 0.69 & 2 & 5 & -0.63 & 0.97 \\
\hline $\begin{array}{l}\text { Keys: (Ana_Pro) Analytica } \\
\text { (Under_Buss) Understandin } \\
\text { (Est_Misstat) Estimating miss }\end{array}$ & $\begin{array}{l}\text { Procedu } \\
\text { Busines } \\
\text { ements }\end{array}$ & $\begin{array}{l}\text { (AIS_Us } \\
\text { onment }\end{array}$ & $\begin{array}{l}\text { Using } \\
\text { a_Go }\end{array}$ & $\begin{array}{l}\text { unti } \\
\text { Eva }\end{array}$ & $\begin{array}{l}\text { Information } \\
\text { on Going }\end{array}$ & $\begin{array}{l}\text { System } \\
\text { Concern }\end{array}$ \\
\hline
\end{tabular}

According to the descriptive results in Table 2, the mean of analytical procedures, AIS usage, understanding business environment, evaluation going concern and estimating misstatements was around 4.05. This result indicate that the vast majority of respondents are agreed to the importance and effect of these variables in auditing process. On the other hand, the standard deviation of these variables ranged between 0.52 and 0.69 , which is mean that a slight number of answers deviated from the average for the vast majority answers. Regarding the normality test, specifically Skewness and Kurtosis, all measures are ranged among -3 and 3, which is indicate that the data are normally distributed (Park, 2008). In addition, to avoid the presence of heteroscedasticity problem when running the 
regression, the heteroscedasticity test was performed. According to the standardised residuals results, the regression is homoscedastic, which is eliminate the probability of encountering heteroscedasticity problem.

\section{- Multivariate Regression Analysis}

In order to test the hypothesized relationships among variables, a regression model analysis was performed. The following three groups of regression models represent the hypothesized mediating effect of the AIS usage on the relationship between analytical procedures and understanding business environment of entities, the evaluation of entities' going concern, and the estimation of potential misstatements in the financial information. The first group of regression models test the direct relationships between analytical procedures and understanding business environment, evaluation going concern of entities, and estimation of misstatements in financial information.

$$
\begin{gathered}
\text { Under_Buss }=a 0+a 1 \text { Ana_Pro }+e i \\
\text { Eva_Go_Co }=b 0+b 1 \text { Ana_Pro }+\varepsilon i \\
\text { Est_Misstat }=c 0+c 1 \text { Ana_Pro }+\mathrm{v} i
\end{gathered}
$$

Where:

Under_Buss $=$ Understanding Business Environment of Entities

Eva_Go_Co $=$ Evaluation of Going Concern of Entities

$a 0, a 1, \mathrm{~b} 0, \mathrm{~b} 1, \mathrm{c} 0, \mathrm{c} 1=$ The constants of the equation
Ana_Pro $=$ Analytical Procedures

Est_Misstat $=$ Estimation of Misstatements

ei, $\varepsilon i, \mathrm{u} i=$ The error term

The second regression model tests the direct relationship between AIS usage (the mediating variable) and analytical procedures (the independent variable).

$$
\text { AIS_Usage }=g 0+g 1 \text { Ana_Pro }+v i
$$

Where:
AIS_Usage $=$ Accounting Information System Usage
Ana_Pro $=$ Analytical Procedures
$\mathrm{g} 0, \mathrm{~g} 1=$ The constants of the equation
$v i=$ The error term

While the third group of regression models test the indirect effect of the AIS usage on the prior mentioned relationships (between analytical procedures and understanding business environment, evaluation going concern of entities, and estimation of misstatements in financial information).

$$
\begin{gathered}
\text { Under_Buss }=d 0+d 1 \text { Ana_Pro }+d 2 \text { AIS_Usage }+r i \\
\text { Eva_Go_Co }=f 0+f 1 \text { Ana_Pro }+f 2 \text { AIS_Usage }+t i \\
\text { Est_Misstat }=h 0+h 1 \text { Ana_Pro }+h 2 \text { AIS_Usage }+s i
\end{gathered}
$$

Where:

Under_Buss $=$ Understanding Business Environment of Entities

AIS_Usage $=$ Accounting Information System Usage

Est_Misstat $=$ Estimation of Misstatements

$r i, t i, s i=$ The error term
Ana_Pro $=$ Analytical Procedures

Eva_Go_Co $=$ Evaluation of Going Concern

$a 0, a 1=$ The constants of the equation

Table 3. The relationship between analytical procedures and understanding business environment, evaluation going concern of entities, and estimation of misstatement in financial information $(\mathrm{N}=164)$

\begin{tabular}{lcccc}
\hline & Under_Buss & Eva_Go_Co & Est_Misstat & AIS_Usage \\
\hline Variables & Coefficient Estimate & Coefficient Estimate & Coefficient Estimate & Coefficient Estimate \\
\hline Independent Variables & & & & \\
\hline \multirow{2}{*}{ Constant } & 0.000 & 0.000 & 0.000 & 0.000 \\
& $(0.122)$ & $(0.155)$ & $(0.981)$ & $(0.023)$ \\
\multirow{2}{*}{ Ana_Pro } & $0.98^{* *}$ & $0.836^{* *}$ & $0.771^{* *}$ & $0.99^{* *}$ \\
& $(0.000)$ & $(0.000)$ & $(0.000)$ & $(0.000)$ \\
\hline
\end{tabular}




\begin{tabular}{lcccc}
\hline R Square & 0.97 & 0.69 & 0.59 & 0.97 \\
Adj. R Square & 0.97 & 0.69 & 0.59 & 0.97 \\
F-value & 6578.88 & 374.82 & 237.89 & 7666.78 \\
Sig. Level & 0.000 & 0.000 & 0.000 & 0.000 \\
\hline
\end{tabular}

P-value (Sig. Level) is reported in parentheses.

* Indicates p value is significant at level $0.05, * *$ Indicates $\mathrm{p}$ value is significant at level 0.01 .

Keys: (Under_Buss) Understanding Business Environment. - (Eva_Go_Co) Evaluation of Going Concern. (Est_Misstat) Estimation of Misstatements in Financial Information. - (Ana_Pro) Analytical Procedures. (AIS_Usage) Accounting Information System Usage.

Table 4. The mediating effect of AIS usage on the relationship between analytical procedures and understanding business environment, evaluation of going concern entities, and estimation of misstatement in financial information $(\mathrm{N}=164)$

\begin{tabular}{lccc}
\hline & Under_Buss & Eva_Go_Co & Est_Misstat \\
\hline Variables & Coefficient Estimate & Coefficient Estimate & Coefficient Estimate \\
\hline Independent Variables & & & \\
\hline \multirow{2}{*}{ Constant } & 0.000 & 0.000 & 0.000 \\
& $(0.628)$ & $(0.805)$ & $(0.001)$ \\
Ana_Pro & $0.465^{* *}$ & $3.486^{* *}$ & $-2.870^{* *}$ \\
& $(0.000)$ & $(0.000)$ & $(0.000)$ \\
AIS_Usage & $0.529^{* *}$ & $-2.678^{* *}$ & $3.679^{* *}$ \\
& $(0.000)$ & $(0.000)$ & $0.000)$ \\
\hline R Square & 0.98 & 0.847 & 0.875 \\
Adj. R Square & 0.98 & 0.845 & 0.873 \\
F-value & 4330.55 & 444.32 & 563.55 \\
Sig. Level & 0.000 & 0.000 & 0.000 \\
\hline
\end{tabular}

$\mathrm{P}$-value (Sig. Level) is reported in parentheses.

* Indicates $\mathrm{p}$ value is significant at level $0.05,{ }^{*}$ Indicates $\mathrm{p}$ value is significant at level 0.01 .

Keys: (Under_Buss) Understanding Business Environment. - (Eva_Go_Co) Evaluation of Going Concern. (Est_Misstat) Estimation of Misstatements in Financial Information. - (Ana_Pro) Analytical Procedures. (AIS_Usage) Accounting Information System Usage.

The results of testing the first group of regression models that test the relationships between the dependent variables and independent variable, and the second regression model that tests the relationship between the mediating and independent variables are showed in Table 3. In addition, Table 4 shows the results of testing the third group of regression models that explore the mediating effect of the AIS usage on the relationships between dependent variables and independent variable.

\section{Results}

In order to attain the objectives of present study, one main hypothesis and two sub-hypotheses were proposed. The main hypothesis indicated that the use of client's accounting information systems by auditors enhances the relationship between the implementation of analytical procedures and understanding the business environment of entities' under audit. To examine this hypothesis three linear regressions tests were performed. The first regression model tested the direct relationship between the implementation of analytical procedures and understanding the business environment of entities' under audit. The coefficient results in table 3 showed that the implementation of 
analytical procedures has a significant positive relationship with understanding business environment of entities' under audit at the significance levels of 0.01 . While the second regression model tested the direct relationship between the implementation of analytical procedures and the use of client's accounting information systems. Once again, the results in table 3 showed that there is a significant positive relationship between the implementation of analytical procedures and the usage of client's accounting information systems at the significance levels of 0.01 . Third regression model tested the mediating effect of the use of client's accounting information systems on the relationship between the implementation of analytical procedures and understanding the business environment of entities' under audit. The coefficient results in table 4 showed that the use of client's accounting information systems has a partial significant positive mediation effect on the relationship between the implementation of analytical procedures and understanding the business environment of entities' under audit at the significant level 0.01 . Accordingly, the main hypothesis of the current study is accepted.

The previous main hypothesis included two sub-hypotheses; the first sub-hypothesis indicated that the use of client's accounting information systems by auditors enhances the relationship between the implementation of analytical procedures and the assessment of company's going concern. To examine this sub-hypothesis, two regression models were tested. First regression model explored the direct relationship between the implementation of analytical procedures and the assessment of company's going concern. The coefficient results in table 3 showed that the implementation of analytical procedures has a significant positive relationship with the assessment of company's going concern at the significant level 0.01 . The second regression model examined the mediating effect of the use of client's accounting information systems by auditors on the relationship between the implementation of analytical procedures and the assessment of company's going concern. Unexpectedly, the coefficient results in table 4 showed that the use of client's accounting information systems by auditors has a full significant negative effect on the relationship between the implementation of analytical procedures and the assessment of company's going concern at the significant level 0.01. This result indicates that the use of client's accounting information systems by auditors limits significantly the effectiveness of the analytical procedures in assessing the going concern of companies. Based on that, the first sub-hypothesis of the current study is rejected.

The second sub-hypothesis indicated that the use of client's accounting information systems by auditors enhances the relationship between the implementation of analytical procedures and the estimation of potential misstatements in financial statements. Two regression models were tested to examine this sub-hypothesis. First regression model examined the direct relationship between the implementation of analytical procedures and the estimation of potential misstatements in financial statements. The coefficient results in table 3 indicated that the implementation of analytical procedures has a significant positive relationship with the estimation of potential misstatements in financial statements at the significant level 0.01 . The second regression model examined the mediating effect of the use of client's accounting information systems by auditors on the relationship between the implementation of analytical procedures and the estimation of potential misstatements in financial statements. The coefficient results in table 4 indicated that the use of client's accounting information systems by auditors has a full significant positive effect on the relationship between the implementation of analytical procedures and the estimation of potential misstatements in financial statements at the significant level 0.01. This result indicates that the use of client's accounting information systems by auditors enhances significantly the effectiveness of the analytical procedures in estimating the potential misstatements in financial statements. Accordingly, the second sub-hypothesis of the current study is accepted.

\subsection{Discussion and Conclusion}

The current study sought from the outset to find out whether the use of client's accounting information systems by auditors enhances the role of analytical procedures in understanding the business environment of entities under audit or not. The previous results showed that the use of client's accounting information systems by auditors not only enhances the role of analytical procedures in understanding the business environment of entities under audit, but also enhances their role in estimating the potential misstatements in financial statements. In this context, the researcher believes that these results may be due to the fact that using client's accounting information systems by auditors in implementing analytical procedures enable auditors to get quick and complete access to the required information from its main sources (Sačer \& Oluić, 2013), which increases the credibility and reliability of this information (Matrood et al., 2019). In addition, it provides auditors more time and less effort to conduct more additional analytical procedures. Accordingly, auditors are able to review more aspects of entities' work to understand their business environments. Further, it also enable auditors to have sufficient time to review more financial transactions and entities' accounts to estimate the presence of potential misstatements in the financial statements (Pura, 2017). (Anderson et al., 2019) who pointed out that the quick access of data will make auditors to spend fewer resources, 
and will enable them to engage in other processes support this conclusion. In addition, (Castka et al., 2020) supported this justification by finding that the use of technology in auditing enhance the volume, variety, velocity, and veracity of auditing work. Similarly, (Tarek et al., 2017) found that despite there are some risks of using clients' accounting information systems, but it still help in improving the implementation of auditing procedures. Many other studies have pointed directly and indirectly to these points such as (Appelbaum et al., 2018) who described the change and development in analytical procedures over time, and (Austin et al., 2020) who explained the effect of technology on auditors' profession.

Conversely, the previous results indicated that the use of client's accounting information systems by auditors does not enhance the role of analytical procedures in assessing the going concern of entities. The researcher expect that the reason of this result is because the going concern issues not only relate to the financial and accounting information systems aspects, but it may also relate to the uncertainty of markets and business. In addition, identifying the going concern issues require auditors to practice high levels of risk assessment, which requires high levels of experience and professionalism, and this is also not closely related to accounting information systems. In this regard, (Shvyreva \& Kruglyak, 2016) found that one of the main problems of professional judgment in evaluating the entities' going concern is the inadequate assessment of business risks. In the past, (Ellingsen et al., 1989) pointed out to the lack of auditors' experience as one of the reasons of the failure in evaluating the going concern of entities. (Bundy, 2019) has also mentioned that the auditor's' problems in making judgment regarding the going concern issues may be relate to selecting the right information, or processing these information. Both of these problems are relate to the auditors' professional experience and not closely related to accounting information systems. Accordingly, the researcher justify that the use of client's accounting information systems by auditors does not enhance the role of analytical procedures in assessing the going concern of entities.

\subsection{Implications of Study}

The results of the current study imply that auditors are able to enhance the effectiveness of analytical procedures in understanding the business environment of entities under audit through using the client's accounting information systems. In addition, they are able to enhance their ability in estimating the potential misstatements in financial information during analytical procedures through using the accounting information systems of clients. These implications relate to the fact that the usage of client's accounting information systems benefit auditors in many aspects such as acquiring credible and reliable information, providing auditors more time and less effort.

On the other hand, the results imply that the use of client's accounting information systems by auditors during analytical procedures in assessing the going concern of entities does not help auditors in getting good results. Even more, the results imply that it limits the effectiveness of analytical procedures in assessing the going concern of entities. More precisely, the use of client's accounting information systems by auditors has counterproductive effects on analytical procedures effectiveness regarding the assessment of entities' going concern.

\subsection{Recommendations of Study}

In light of the previous results, the study presents three main recommendations of auditors. First one, auditors should convince clients of the necessity to use their accounting information systems, when signing the contract for auditing mission, to obtain the best results in terms of understanding the business environment of entities and estimating the potential misstatements in financial statements. The second, auditors should acquire the necessary information technology skills to enable them to use the information systems (either accounting or administrative) of clients effectively to increase the effectiveness of analytical procedures in auditing process. Finally, despite the benefits of using client's accounting information systems in enhancing analytical procedures effectiveness, auditors should use additional resources in the implementation of analytical procedures to ensure reliability of results, especially with regard to assessing the going concern of entities.

\subsection{Limitation of Study and Suggestions for Future Studies}

It should be noted that there were some limitations that surrounded the current study. These limitations are, limiting the research to the Jordanian auditing setting; therefore, the results of the current study cannot be generalized to other auditing settings in other countries. Accordingly, the current study provide a platform for other researchers to carry out similar studies in other auditing settings in other countries to ensure the possibility of generalizing the results.

In addition, collecting and analyzing data of the current study is limited on the quantitative methods, which may be affected by the respondents' bias. Consequently, there is an opportunity for other researchers to carry out similar studies using other methods (especially qualitative methods) to ensure the validity of the current results. 
Further, in light of the global technological revolution, other researchers are advised to carry out other studies in different countries to explore the impact of using technology on the different stages of auditing process, such as the planning process, risk assessment processes, initial tests process, and auditing results.

\section{Acknowledgements}

The author would like to acknowledge the administration of Zarqa University - Jordan, which provided all the required facilities to conduct this research. Further, he would like to acknowledge every auditor (qualified and unqualified) in Jordanian auditing firms who helped me by filling out study questionnaires and providing explanations for their answers.

\section{Refrences}

Adomavicius, G., Bockstedt, J., Curley, S. P., Zhang, J., \& Ransbotham, S. (2019). The Hidden Side Effects of Recommendation Systems. MIT Sloan Management Review, 60(2), 1-18.

Afshar, M. S., Pourheidari, O., Al-Gamrh, B., \& Jahanshahi, A. A. (2019). Audit management, need for closure and detection of misstatements. Journal of Accounting in Emerging Economies, 9(2), 237-250.

AL-Amro, S. A., Alnawaiseh, M. B., Bader, A. A., \& Alnawaiseh, M. A. L. I. (2017). The Quality of Financial Reports in the Risks of Electronic Accounting Information Systems in the Jordanian Commercial Banks. International Journal of Economic Research, 14(10), 1-16.

Anderson, S. B., Hobson, J. L., \& Peecher, M. E. (2019). The Joint Effects of Rich Data Visualization and Audit Procedure Categorization on Auditor Judgment. Working paper, University of Illinois.

Appelbaum, D., Kogan, A., \& Vasarhelyi, M. (2018, June). Analytical procedures in external auditing: A comprehensive literature survey and framework for external audit analytics. Journal of Accounting Literature, 40, 83-101.

Appelbaum, D., Kogan, A., Vasarhelyi, M., \& Yan, Z. (2017, May). Impact of business analytics and enterprise systems on managerial accounting. International Journal of Accounting Information Systems, 25, 29-44.

Austin, A. A., Carpenter, T. D., Christ, M. H., \& Nielson, C. (2020, March). The Data Analytics Journey: Interactions among Auditors, Managers, Regulation, and Technology. SSRN. https://doi.org/10.2139/ssrn.3214140

Bundy, S. (2019). Binary Bright-Line Decision Models for Going Concern Assessment: Analysis of Analytical Tools for Bankruptcy Prediction Considering Sensitivity to Materiality Thresholds. Doctor of Philosophy (PhD), University of Kentucky, UKnowledge.

Byrnes Paul, E., Al-Awadhi, A., Gullvist, B., Brown-Liburd, H., Teeter, R., Warren, J. D., \& Vasarhelyi, M. (2018). Evolution of Auditing: From the Traditional Approach to the Future Audit1. In Y. C. David, C. Victoria, \& A. V. Miklos (Eds.), Continuous Auditing (pp. 285-297). Emerald Publishing Limited.

Castka, P., Searcy, C., \& Mohr, J. (2020, June). Technology-enhanced auditing: Improving veracity and timeliness in social and environmental audits of supply chains. Journal of Cleaner Production, 258, 120773.

Dolinska, O. (2019). Improvement of the Model of Using Analytical Procedures at Internal Auditing of A Bank. EUREKA: Social and Humanities, 4, 16-23.

Ellingsen, J., Pany, K., \& Fagan, P. (1989). SAS No. 59: How to Evaluate Going Concern. Journal of Accountancy, 167(1), 24-31.

Guragai, B., Hunt, N. C., Neri, M. P., \& Taylor, E. Z. (2017). Accounting Information Systems and Ethics Research: Review, Synthesis, and the Future. Journal of Information Systems, 31(2), 65-81.

Khazanchi, D. (2005). Information Technology (IT) Appropriateness: The Contingency Theory of "Fit" and it Implementation in Small and Medium Enterprises. Journal of Computer Information Systems, 45(3), 88-95.

Leonov, P., Kozhina, A., Leonova, E., Epifanov, M., \& Sviridenko, A. (2020). Visual analysis in identifying typical indicators of financial statements as an element of artificial intelligence technology in audit. Procedia Computer Science, 169, 710-714.

Matrood, A. K., alrazaq, D. N. A., \& Khilkhal, N. S. (2019). The Impact of Applying Analytical Procedures by External Auditor in Accordance with ISA 520 on Audit Performance Improvement: An Exploratory Study in the Iraqi Audit Firms and Companies. Academy of Accounting and Financial Studies Journal, 23(1), 1-21. 
McCallig, J., Robb, A., \& Rohde, F. (2019, June). Establishing the representational faithfulness of financial accounting information using multiparty security, network analysis and a blockchain. International Journal of Accounting Information Systems, 33, 47-58.

Moolman, A. M. (2017). The Usefulness of Analytical Procedures, Other Than Ratio And Trend Analysis, For Auditor Decisions. International Business and Economics Research Journal (IBER), 16(3), 171-184.

Nazarova, K., Nazarova, K., Hordopolov, V., Kopotiienko, T., Miniailo, V., \& Diachenko, Y. (2019). Audit in the State Economic Security System. Management Theory and Studies for Rural Business and Infrastructure Development, 41(3), 419-430.

Pallant, J. F. (2005). SPSS survival manual: 'A step by step guide to data analysis using SPSS version 12 (2nd ed.). Two Penn Plaza, NY, S.S.A. Open University Press.

Park, H. M. (2008). Univariate Analysis and Normality Test Using SAS, Sata, and SPSS. Technical Working Paper. The University Information Technology Services (UITS) Center for Statistical and Mathematical Computing, Indiana University.

Pura, R. (2017). Effects of Auditor Competence, Information Technology, Accounting Information Systems and Organizational Commitment on Auditors' Performances at the State Audit Agency, in South Sulawesi. Scientific Research Journal (SCIRJ), V(X), 16-22.

Rose, A. M., Rose, J. M., Suh, I., \& Thibodeau, J. C. (2020). Analytical Procedures: Are More Good Ideas Always Better for Audit Quality?. Behavioral Research in Accounting, 32(1), 37-49.

Rozario, A. M., \& Vasarhelyi, M. A. (2018). Auditing with Smart Contracts. The International Journal of Digital Accounting Research, 18, 1-27.

Sačer, I. M., \& Oluić, A. (2013). Information Technology and Accounting Information Systems' Quality in Croatian Middle and Large Companies. Journal of Information and Organizational Sciences, 37(2), 117-126.

Shvyreva, O. I., \& Kruglyak, Z. I. (2016). Problems of Professional Judgment Application in Evaluating the Company's Going Concern. Indian Journal of Science and Technology, 9(14).

Smith, J. L., \& Stephens, N. M. (2020). The Reel Wheel: Using Analytical Procedures as Substantive Tests of Account Balances. Issues in Accounting Education, 35(1), 13-24.

Sori, Z. M. (2009). Accounting Information Systems (AIS) and Knowledge Management: A Case Study. American Journal of Scientific Research, (4), 36-44.

Tarek, M., Mohamed, E. K. A., Hussain, M. M., \& Basuony, M. A. K. (2017). The implication of information technology on the audit profession in developing country: Extent of use and perceived importance. International Journal of Accounting and Information Management, 25(2), 237-255.

Van der Veeken, H. J. M. v. d., \& J.F.Wouters, M. (2002). Using accounting information systems by operations managers in a project company. Management Accounting Research, 13(3), 345-370.

Vanstraelen, A., \& Schelleman, C. (2017). Auditing private companies: what do we know?. Accounting and Business Research, 47(5), 565-584.

\section{Note}

Note 1. Source: http://jacpa.org.jo/en-us/home.aspx

\section{Copyrights}

Copyright for this article is retained by the author(s), with first publication rights granted to the journal.

This is an open-access article distributed under the terms and conditions of the Creative Commons Attribution license (http://creativecommons.org/licenses/by/4.0/). 